\title{
Scanning electron microscope studies on the radula teeth of four species of marine gastropods from the Gulf of Mannar, India
}

\author{
V.VENKATESAN ${ }^{1}$, P. RAMESHKUMAR ${ }^{2}$ AND A. BABU ${ }^{3}$ \\ ${ }^{1}$ ICAR-Central Marine Fisheries Research Institute, Kochi - 682 018, Kerala, India \\ ${ }^{2}$ Regional Centre of ICAR-Central Marine Fisheries Research Institute, Mandapam Camp - 623 520, Tamil Nadu, India \\ ${ }^{3}$ Centre for Advanced Studies in Marine Biology, Annamalai University, Parangipettai - 608 502, Tamil Nadu, India
}

\begin{abstract}
In this study scanning electron microscopy (SEM) was used to elucidate the surface morphology of radula teeth of four species of marine gastropods belonging to muricids and tonnoideans from the Gulf of Mannar. The species studied were Tonna dolium (Linne, 1758), Phalium glaucum (Linne, 1758), Murex virgineus (Roding, 1798) and Rapana rapiformis (Born, 1778). The radulae of muricid gastropods were of stenoglossan type $(1+\mathrm{R}+1)$ while the radulae of tonnoidean gastropods were of taenioglossate type $(2+1+\mathrm{R}+1+2)$. Very large radula and solid teeth in all four species indicate that they are well adapted to capture of prey and showed characteristic representation of the sharp and pointed apex. The shafts of the teeth of $R$. rapiformis, $T$. dolium and $M$ virgeneus are thickened and expanded at the base to form a butt and the basal spur as well as their marginal and central teeth are sickle shaped. Radulae of both groups are well suited for tearing and rasping. The examination of the central tooth, the lateral and marginal ones, by SEM provides further information for species differentiation.
\end{abstract}

Keywords: Gastropods, Muricids, Radula, Scanning electron microscopy, SEM, Tonnoideans

The Gastropoda is represented by species with tremendous adaptative success. This characteristic allowed the appearance of many forms of feeding and with it, many strategies of capture and food processing. Much of the diversity achieved by the gastropods relates to the evolutionary shifts in radular structure, which have led to exploitation of a variety of food sources. The muricids like Rapana rapiformis (Born, 1778), Murex virgineus (Roding, 1798) and tonnoideans like Tonna dolium (Linne, 1758), Phalium glaucum (Linne, 1758) are well known to be long lived, widely distributed geographically, unparalleled in any other gastropod group. They are voracious carnivores or predators, occupying important niches in many food webs. These medium-sized gastropods are commercially important, mostly landed as bycatch of shrimp trawlers at the landing centres of Gulf of Mannar region along the south-east coast of India. They play an important role in the economy of the region as they are collected to make curios for shell handicraft trade and for local consumption (Appukkutan and Ramadoss, 2000).

Radula, a broad ribbon covered with a few to many thousand teeth, is a unique feeding organ and is one of the distinguishing features of molluscs (Bradner and Kay, 1996). The radulae are useful to grind food. It has also other functions, depending upon the different feeding regimes of gastropods, such as rasping and scrapping of hardened microalgae, operating like 'rakes' or 'broom' for gathering loose microalgae and detritus, rasping and physical shell removal during drilling, penetration of test and ejection like a harpoon into the prey. The shapes and structures of molluscan radular teeth are often unique to a species or a genus and thus its morphology is an important tool for species identification (Reid and Mak, 1999; Franklin, 2007). Radula has been used to solve the problems of critical species, which are practically impossible to set apart based only on morphological analysis of the shell or soft parts (Simison and Lindberg, 1999).

With its high resolution, the scanning electron microscope (SEM) is the ideal means to observe, the three-dimensional relationships of the translucent radular tooth (Kohn et al., 1972; Freeman and Silva, 1973). SEM studies on radulae of gastropods have been done elsewhere (Freeman and Silva, 1973; Houart, 1992; Mutlu, 2004). Studies from India have been restricted to few gastropods and cephalopods (Stella, 1995; Samuel and Paterson, 2003; Franklin et al., 2007; Ramesh and Ravichandran, 2008; Aruarasan et al., 2011). In the present study, an attempt was made to elucidate the anatomy of the radulae of two species each under muricids and tonnoideans from the Gulf of Mannar.

Adult specimen of muricids viz., $R$. rapiformis and $M$. virgineus and tonnoideans viz., $T$. dolium and P. glaucum were collected from the shrimp trawl 
bycatch of Mandapam fish landing centre $\left(09^{\circ} 16^{\prime} 43.1^{\prime \prime} \mathrm{N}\right.$; $\left.79^{\circ} 09^{\prime} 44.4^{\prime \prime} \mathrm{E}\right)$ of Gulf of Mannar in November 2010. The animals were brought to the laboratory and were fixed in $10 \%$ buffered formalin, for dissecting at a later point of time. The shell length of animals was measured and outer hard shells of animals were cracked in a vice. Care was taken not to damage the soft body parts. Proboscis portion of each specimen was dissected and the radula removed. To dissolve the attached connective tissue and mucus, the radula was placed in dilute sodium hypochlorite $(\mathrm{NaOCl})$ for $1 \mathrm{~h}$, adhering tissues were removed using a fine brush and then rinsed in distilled water and mounted on clear glass slides. Radulae were dehydrated in ascending series of alcohol grades $(30,50,70,80,90$, and 95\%), subsequently dehydrated and then processed to the next step i.e., critical point drying, followed by gold sputter coating thereby making them suitable for the SEM observation. The radulae were mounted on the SEM stub and were photomicrographed.

The shape and arrangement of teeth on the radula of gastropods is an adaptation to the feeding regime of the species. The number, shape and specialised arrangement of teeth in each transverse row are consistent on a radula and the different patterns can be used as a diagnostic characteristic to identify the species in many cases. Each row of radula teeth consists of one central or rachis tooth $(\mathrm{R})$ followed by one or more lateral teeth $(\mathrm{L})$ on each side, which are designated by a specific number or the alphabet $\mathrm{D}$, in case the outer lateral teeth is dominant, and then one or more marginal teeth $(\mathrm{M})$, which are designated by a specific number or $\infty$, in case they are large in number. There are five basic types of radulae: docoglossan or stereoglossan, rhipidoglossan, taenioglossan, stenoglossan or rachiglossan and toxoglossan and the arrangement of teeth is expressed in a dental formula (Fig. 1). First three types of radulae are meant for herbivorous gastropods, as they require many teeth for scraping the algae, while the rest are for carnivorous species, which require fewer teeth, especially laterals and marginals.

The dental formula of the examined specimens of the Muricoidea and Tonnoidea super family were $1+\mathrm{R}+1$ (stenoglossan type) and $2+1+\mathrm{R}+1+2$ (taenioglossan type) with parallel rows of teeth. Bottom of the radula is made up of a radular ribbon to which the denticles are attached. Radular structures of the specimens studied presented the following characteristics:

Rapana rapiformis: $R$. rapiformis, commonly known as turnip-shaped rapa is a commercially important ornamental gastropod, belonging to the family Muricidae. This is a widely distributed species throughout the Gulf of Mannar. The meat of $R$. rapiformis, inhabiting subtidal and intertidal areas is consumed by a few coastal fishermen of Tamil Nadu.

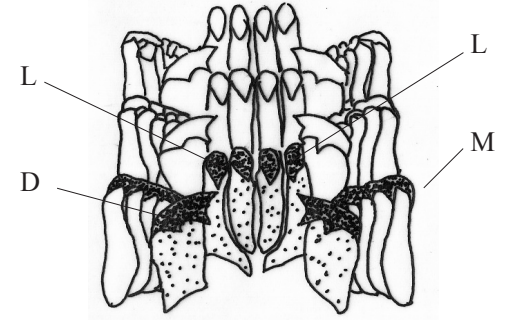

$$
\begin{gathered}
\text { Docoglossan (Stereoglossan) } \\
\mathrm{F}: 3+\mathrm{D}+2+\mathrm{R}+2+\mathrm{D}+3 \\
\text { or }: 3+\mathrm{D}+2+0+2+\mathrm{D}+3
\end{gathered}
$$

(a)

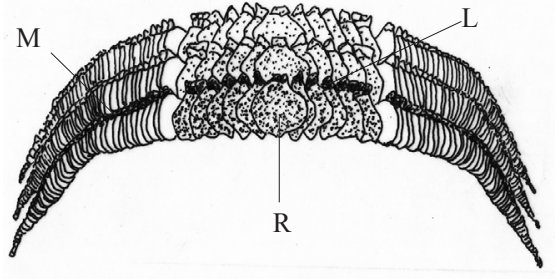

Rhipidoglossan $\mathrm{F}: \infty+5+\mathrm{R}+5+\infty$ or : $\infty+\mathrm{D}+4+\mathrm{R}+4+\mathrm{D}+\infty$

(b)

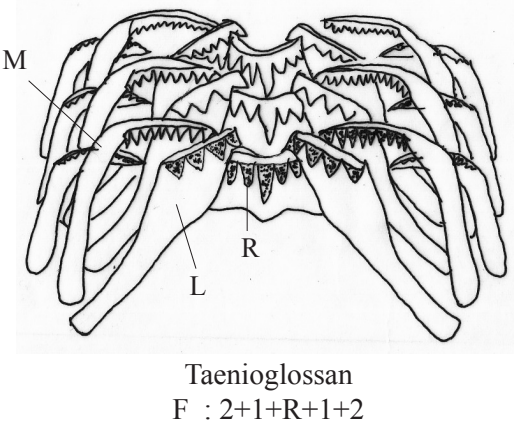

(c)

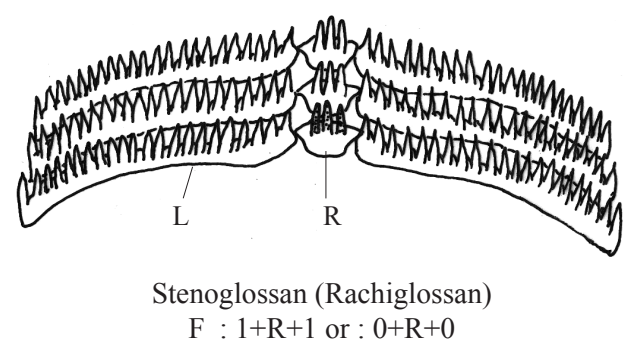

(d)

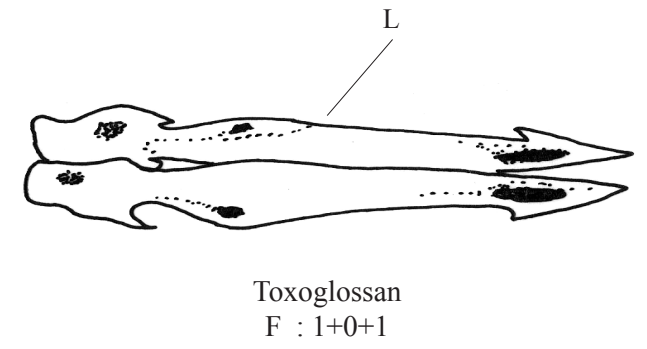

(e)

Fig. 1. Diagrammatic view of the five basic types of radula with dental formula F - Formula, R - Rachis, L - Lateral, D - Dominant, M - Marginal, IM - Inner marginal, OM - Outer marginal 
The radula of $R$. rapiformis is located in the radular sac, which lies ventral to the anterior oesophagus. Radula showed the typical stenoglossan pattern $(1+\mathrm{R}+1)$, with one rachidian or central row of teeth flanked on each side by lateral teeth. The rachidian teeth have three large cusps, whereas lateral teeth have no cusps. The central tooth is elongated and is broader at the base. The posterior ends of all teeth, especially lateral ones are sharp pointed, curving inwards. Some of the rachidian teeth were observed to be broken or reduced in size than the marginal teeth found in the same transverse rows (Fig. 2a, b).

Murex virgineus: $M$. virgineus, commonly known as virgin murex is a widely distributed species throughout the Gulf of Mannar. This muricid, inhabiting subtidal and intertidal areas is an important species of ornamental/ edible gastropod, belonging to the Muricidae family. The radular formula of this species was identified as $1+\mathrm{R}+1$ (stenoglossan type) and the radula comprised a central row of rachidian teeth flanked on each side by lateral teeth. Each rachidian plate is with a curved base and three cusps that project over the basal plate of the next row, the

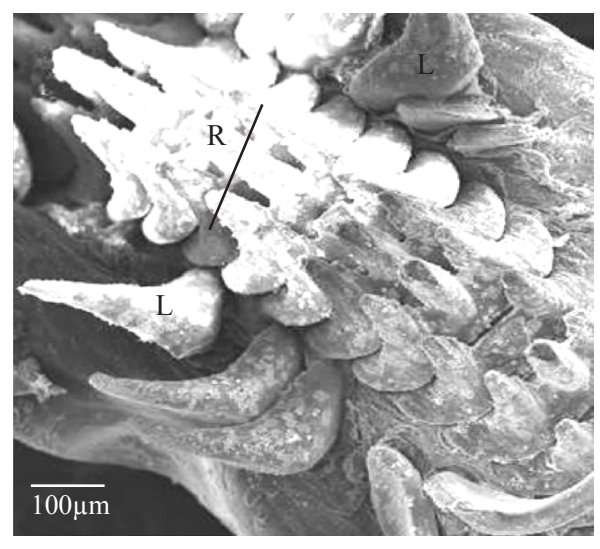

(a) middle cusp is the longest and sickle-shaped. The lateral teeth with large base and curved tip are sickle-shaped. All the teeth in a row are quite large, forming triangular shaped inward curve and when the radula is at rest they lean among themselves and their tips end in sharp curves. Teeth of this species are relatively large and long, but the bases are thin compared to $R$. rapiformis. In aerial view, the radular teeth structure as a whole looks like crab legs (Fig. 2c, d).

Tonna dolium: T. dolium, commonly known as spotted tun, is a commercially important ornamental gastropod, inhabiting intertidal areas is also consumed by selected coastal fishermen of Tamil Nadu. The radular formula of this species studied here is $2+1+\mathrm{R}+1+2$ (taenioglossan type), with straight rows of teeth. The seven teeth are arranged as: the central tooth is flanked on each side by a lateral tooth and two marginal ones (inner and outer marginal teeth). The posterior ends of the basal plate are sharp-pointed, curving inwards, forming sickle-shaped teeth relatively small, narrow-armed, shallowly $\wedge$ shaped belonging to the family Tonnidae. The meat of T. dolium,

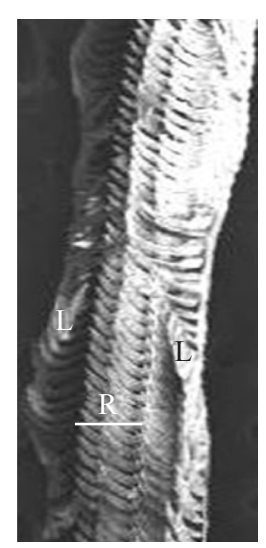

(c)

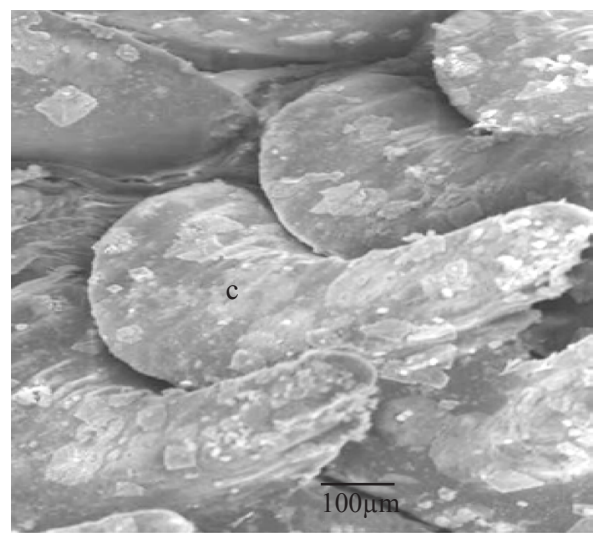

(b)

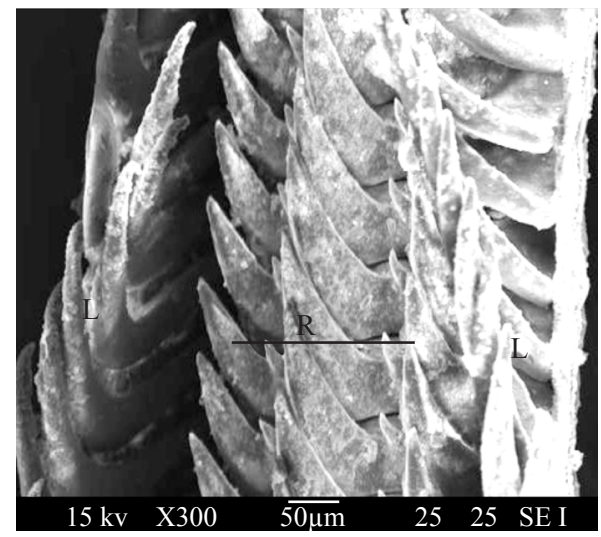

(d)

Fig. 2. SEM images of the radulae of the muricid gastropods: (a) and (b) - Murex virgineus, (c) and (d) - Rapana rapiformis R - Rachidian (central tooth), L - Lateral, C - Cusp 
central tooth having small interlocking basal processes; near the extremity of each basal arm is a small downward projecting process that interlocks adjacent centrals; lateral teeth elongate and are massive. jaw plates are large. The marginal teeth are large, heavily built and are sharply curved and long. The inner teeth are relatively massive, with square base, whereas the outer one has a small base (Fig. 3a, b).

Phalium glaucum: P. glaucum (Family: Cassidae) inhabiting in the intertidal areas is also used for both ornamental and edible purposes. The radula showed the typical taenioglossan pattern $(2+1+\mathrm{R}+1+2)$. The central tooth has eleven cusps and the main central cusp is relatively elongated and large. It has a spine shaped or apex shaped cusp, ending in a sharp point and five flanking cusps, becoming smaller distally on each side; having basal platform with marginal ridges of moderate size. The lateral tooth has a main cusp as well and four shorter apex shaped cusps of equal size, on each side. Lateral teeth are relatively bigger than the central ones. The most distal of these three cusps is very small, bluntly pointed and is always oriented inwards. The marginal outer and inner

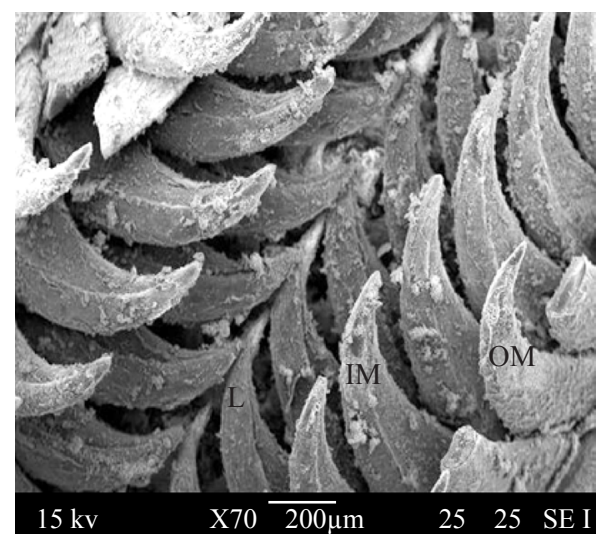

(a)

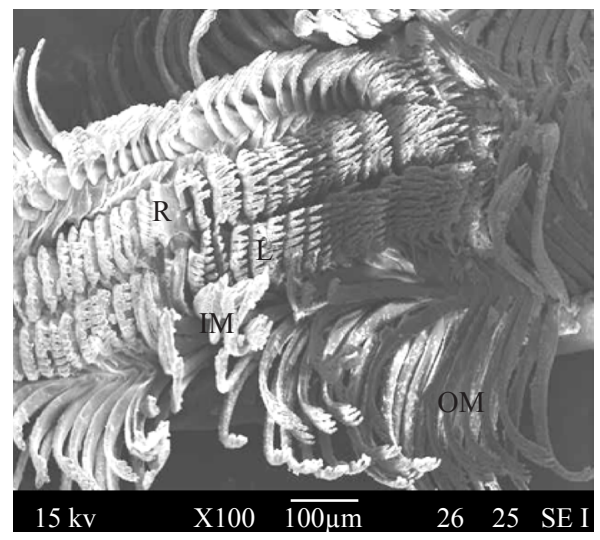

(c) teeth are quite elongated, thin, and spatula shaped. They fold one over the other, with 4-5 small cusps of equal size at the outer margin (Fig. 3c, d).

Observations on the surface morphology of the radulae in the present study are quite related to the radular morphology of other muricids (Carriker, 1969; Houart, 1992; Mutlu, E. 2004; Harding et al., 2008) and tonnoidean gastropods (Waren, 1996; Harasewych and Kantor, 2002) studied elsewhere. The radular structures of all the species studied are typical to their families or groups. The radula has been used as a main tool in the systematic studies of gastropods (Reid and Mak, 1999). The radular structures of $R$. rapiformis are very similar to the ones observed by McLean and Andrade (1982) for the species Trophon bahamondei, belonging to the same family, collected off central Chile. Radular morphology of $R$. rapiformis is also similar to that observed by Harasewych (1984) while studying the muricid Trophon geversianus, an intertidal gastropod, of tropical and subtropical regions of Chile. The radular structures of $M$. virgineus described in the present study are closely related to that observed by Harasewych (1984) for

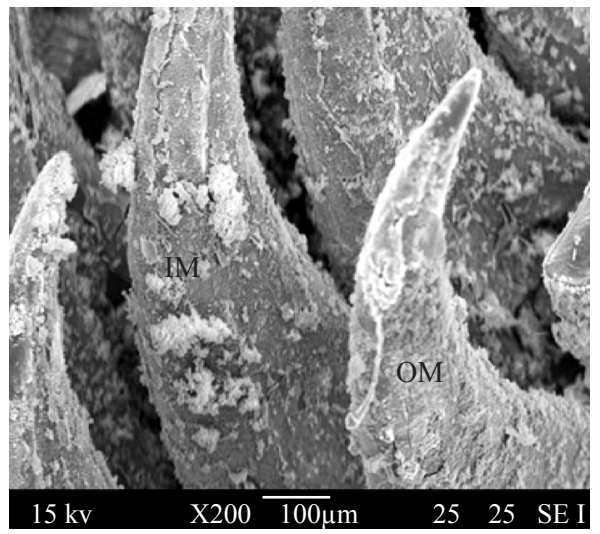

(b)

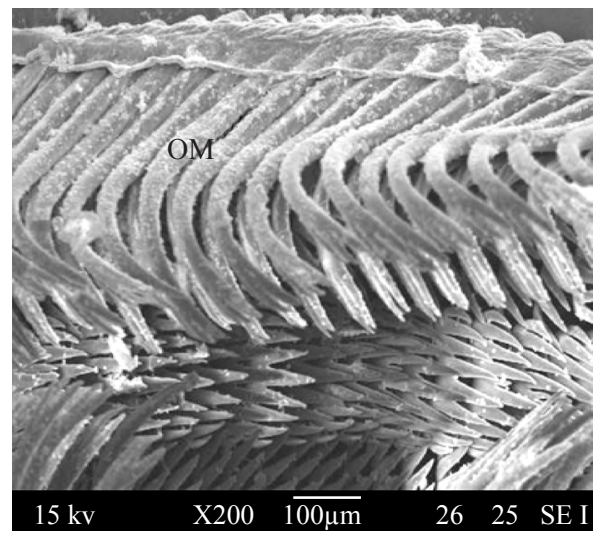

(d)

Fig. 3. SEM images of the radulae of the tonnoidean gastropods: (a) and (b) - Tonnadolium, (c) and (d) - Phaliumglaucum R - Rachidian (central tooth), L - Lateral, IM - Inner marginal tooth, OM - Outer marginal tooth 
the muricid, Nucella lamellosa, collected from the north-western coast of North America. The radular morphology of $P$. glaucum in the present study was found similar to those reported by McLean and Andrade (1982) for the tonnoidean gastropod, Fusitriton magellanicus of central Chile. The radular structures of $P$. glaucum from the present study also looked similar to the species Cerithidea scalahformis falling under the same order, collected from the north-western coast of North America (Harasewych, 1984 ).

SEM images of all the four species revealed that they have very large radula, rigid shafts and solid teeth, indicating that all are good predators. Radular tooth of all the four species in SEM images appear to be well adapted to capture sedentary prey. The teeth of all the species are arranged so closely that it becomes practically impossible for the prey to pull away from them. SEM images of radula from muricid species showed that they possess teeth, especially lateral ones, with large base and curved tip which is often sickle shaped (Fig. 2). Such a teeth structure would be well suited to capture a slow moving prey. Carriker (1969) and Carriker et al. (1974) while studying the muricid Urosalpinx spp. found that the central rachidian tooth in each transverse row is responsible for most of the rasping and physical shell removal during drilling, while the marginal teeth synchronously tear flesh from the prey. Hence, the rachidian teeth show reduction in size with use, than marginal teeth (Carriker et al., 1974). Tonnoideans are known to drill hole into the shell of their prey to reach the soft parts with their proboscis, and it requires more teeth for tearing, rasping and grinding activity during feeding. In the present study, the tonnoideans $T$. dolium and $P$. glaucum were found to have 7 teeth in a row with or without sharp, conical cusps well suited for the purpose (Fig. 3). Radula grows continuously during the gastropod's life, with new rows of teeth being formed posteriorly in the radular sac to replace the worn denticles cast off at the anterior end (Carriker, 1981). Gastropods replace their radular teeth throughout their entire life cycle (Runham and Thornton, 1967).

\section{Acknowledgements}

The authors express their sincere thanks to the Director, ICAR-CMFRI, Kochi for constant encouragement and facilities provided for conducting the study.

\section{References}

Appukuttan, K. K. and Ramadoss, K. 2000. Edible and ornamental gastropod resources. In: Pillai, V. N. and Menon, N. G. (Eds.), Marine fisheries research and management. Central Marine Fisheries Research Institute, Kochi, p. 525-535.

Arularasan, S., Kesavan, K. and Lyla, P. S. 2011. Scanning electron microscope (SEM) studies of radula of the dog conch Strombus canarium (Gastropoda: Prosobranchia:
Strombidae). Eur. J. Exp. Biol., 1(1): 122-127.

Bradner, H. and Kay, A. 1996. Atlas of cowrie radulae (Mollusca: Gastropoda: Cypraeoidea: Cypraeidae). The Festivus, 28: Suppl., 1-9.

Carriker, M. R. 1969. Excavation of boreholes by the gastropod, Urosalpinx: an analysis by light and scanning electron microscopy. Amer. Zool., 9: 917-933.

Carriker, M. R., Schaadt, J. G. and Peters V. 1974. Analysis by slow-motion picture photopograph and scanning electron microscopy of radular function in Urosalpinx cinerea follyensis (Muricidae, Gastropoda) during shell penetration. Mar. Biol., 25: 63-76.

Carriker, M. R. 1981. Shell penetration and feeding by Naticacean and Muricacean predatory gastropods: A synthesis. Malacologia, 20: 403-422.

Franklin, J. B., Fernando, S. A., Chalke, B. A. and Krishnan, K. S. 2007. Radular morphology of Conus (Gastropoda: Caenogastropoda: Conidae) from India. Moll. Res., 27(3): 111-122.

Freeman, S. E. and Silva S. R. 1973. Scanning electron microscope studies on the radula teeth of two species of marine gastropods. Micron, 4: 247-255.

Harasewych, M. G. 1984. Comparative anatomy of four primitive muricacean gastropods: implications for Trophonine phylogeny. Amer. Malac. Bull., 3(1): 11-26.

Harasewych, M. G. and Kantor, Y. I. 2002. Buccinum thermophilum (Gastropoda; Neogastropoda, Buccinidae), a new species from the endeavour vent field of the Juan De Fuca ridge. J. Mol. Stud., 68: 39-44.

Harding, J. M., Gera, S. M. and Mann, R. 2008. Radula morphology in veined rapa whelks, Rapana venosa (Valenciennes, 1846) (Gastropoda: Muricidae) from Chesapeake Bay, USA. The Nautilus, 122(4): 217-227.

Houart, R. 1992. Description of a new species of Chicoreus (S.S) (Gastropoda: Muricidae) from Kalimantan (Borneo). Apex, 7(1): 27-30.

Kohn, A. J., Nybakken, J. W. and Van Mol, J. J. 1972. Radula tooth structure of the gastropod Conus imperialis elucidated by scanning electron microscopy. Science, 176: 49-51.

McLean, J. H and Andrade, V. H. 1982. Large archibenthal gastropods of central Chile: collections from an expedition of the R/V ANTON BRUUN and the Chiliean shrimp fishery. Contr. Sci., 342: 1-20.

Mutlu, E. 2004. Sexual dimorphisms in radula of Conomurex persicus (Gastropoda: Strombidae) in the Mediterranean Sea. Mar. Biol.,145: 693-698.

Ramesh, R. and Ravichandran, S. 2008. Feeding biology with reference to algal preference and scanning electron microscopy studies on the radula of Turbo brunneus. Trends Applied Sci. Res., 3(2): 189-195. 
Reid, D. G. and Mak, Y. M. 1999. Indirect evidence for ecophenotypic plasticity in radular dentition of Littoraria species (Gastropoda: Littorinidae). J. Moll. Stud., 65: 355-370.

Runham, N. W. and Thornton, P. R. 1967. Mechanical wear of the gastropod radula - A scanning electron microscope study. J. Zool. Lond., 153: 445-452.

Stella, C. 1995. Studies on the taxonomy and eco-biology of Chicoreus species (Class: Gastropoda: Family: Muricidae) from Parangipettai waters, south-east coast of India. Ph.D. Thesis, Annamalai University, India, 195 pp.
Samuel, D. V. and Patterson, J. 2003. A comparative study on the radula of three Coleoid Cephalopods. South Pacific Study, 24(1): 33-38.

Simison, W. B. and Lindberg, D. R. 1999. Morphologial and molecular resolution of a putative cryptic species complex: a case study of Notoacmea fascicularis (Menke, 1851) (Gastropoda: Patellogastropoda). J. Moll. Stud., 65: 99-109.

Waren, A. 1996. New and little known mollusca from Iceland and Scandinavia. Sarsia, 81: 197-245.

Date of Receipt $\quad: \quad 16.07 .2012$

Date of Acceptance : $\quad 09.11 .2015$ 